\title{
How a Season Differs from Year to Year
}

\section{The Rational Causes of Variations in Our Summers and Winters \\ By Sir Frederic Stupart, Director of the Meteorological Office, Toronto}

A PвовLEM which still remains unsolved in Meteorology is why corresponding seasons in different years differ so much in character. In a previous paper ${ }^{1}$ entitled "Is the Climate Changing" the various condition in nature which lead to the distinctive features of the climatic zone were given as follows:

1. Distance from the equator.

2. Geographical position in relation to land and sea. 3. Altitude.

4. The prevalling winds, the outcome of a genera atmospheric circulation.

It was pointed out that of the factors enumerutel, distance from the equator, distance from the sea, and altitude were, in short periods of history, constunts, and that unless deforestation could be shown to have had an appreclable effect, we are thrown back to the assumption that climatic variations through comparatively short periods of history must result from change in atmospheric circulation, which changes must be further investigated.

If to variation in the atmospheric circulation are due the pulsations in climate which we know have occurrer down through the centuries and in our own time, how much more certain is it that the variations from yea to year are attributable to a somewhat similur cuuse?

The question to be considered then is-apart from the constant factors which produce the distinctive characteristics of the climatic zones--what are the more direct varying conditions which lead to abno malities and is it possible to account for these chang ing conditions?

The past two winters, that of 1918 and that of 1919 were in strong contrast; the former was phenomenall cold and the latter phenomenally mild. Why the difference?

It will be in order to describe what may perhaps be termed the normal distribution of atmospheric pressure, and then show in what respect the distribution of atmospheric pressure in these two zears has differed from normal and led to unusual air movements.

Observations on the surface of the earth and of the atmospheric currents, as indicated by clouds and the ballon-sonde, indicate a primary distribution of atmospheric pressure and a general air circulation about as follows:

$A$ belt of low pressure around the globe in the equatorial regions; both northward and southward the pressure increases towards a belt of high pressure between $25^{\circ}$ and $30^{\circ}$ north and south latitude and the outcome of this distribution is the northeast and southeast trade winds of the Tropics. As the latitude ineast trade winds of the Tropics. As the latitude in-
creases beyond the high pressure belts, the pressure creases beyond the high pressure belts, the pressure
gradually diminishes and the barometric gradient of the middle and higher latitudes produces the prevalent westerly winds. If the globe were all land or all water this distribution of atmospheric pressure, and hence the winds, would probably be almost constant and simply fluctuate somewhat in latitude with the annual change in the sun's declination.

But the earth is part land and part water and the very different absorptive and radiating properties of land and water lead to a secondary atmospheric distribution which changes with the seasons and $1 \mathrm{~s} \mathrm{im}$. pressed on the primary system. In the colder seasons over the continents, the high pressure of the primars helts becomes higher and in both the Eastern Hemisphere and the Western Hemisphere overspreads towards higher latitudes, whlle in the warmer seasons wards higher latitudes, while in the warmer seasons
the high pressure either diminishes or disappears anrl the high pressure either dim
low pressure takes its place.

low pressure takes its place.
As far as is known the great cold waves which form over the northern parts of the continents in winter are the outcome of the radiation of heat from the land, and lead to anticyclonic conditions. In normal seasons the anticyclones and cold waves thus formed in the north, move southeastward to lower latitudes, alternating with but outbalancing the low areas which move eastward, carried with the general drift of the primary system of circulation.

The mean barometric charts show how the resultant of atmospheric changes and movements is high pressure over the continents in winter while in the North $\mathbf{P a}$ clfic and North Atlantic the barometer is low. These low centers have been termed centers of action.

But a study of monthly charts of single winters shows a marked variation in the contrast between the -From Jour., Roy. Aetron. Soo., Canada (Toronto).
your., Roy. Aetran. Boo., Canada, 1917, V. R, p. 197. continental high pressure and the ocean low. In some winters in Canada, it is high pressure in northern lat1tudes which dominates our weather, while in other winters the continental HIGн seems to be overpowered by the Pacific Low which most persistently in the form of deep cyclonic areas prevents the formation of anticyclones over Yukon and the Mackenzie River Basin, and the result is the formation of barometric gradients the result is the formation of barometric gradients
which produce a general flow of air from south to north over Canada and hence higher temperature than the normal.

In the early part of the winter of 1917-18 the anticy clonic type was more pronounced than in any other winter on record, and with most persistent areas of high barometer coming in over Yukon, perhaps indeed offshoots from the great Siberian winter anticyclone, the North Pacific Low pressure was situated much further south than usual and its offshoots, in the form of travelling low areas passed into Canada over south ern British Columbia and thence kept away to the southward, and the result was a prevalence of northerly winds, not only in the western provinces but also in Eastern Canada.

During the winter just closed we find conditions in strong contrast to those of the previous year; the North Pacific Low was extremely energetic and in a stream of offshoot cyclonic areas which impinged on the northern Alaskan coast, prevented the formation of anticyclonic conditions, and passing first southeastward, finally moved eastward as dispersing areas across the western provinces, there giving most persistent gradients for southerly and southwesterly winds with unseasonably high temperature. I shall not go into de talls regarding the various months, contenting myself with this general outline.

The problem which has then first to be solved would appear to be that concerning the centers of action in the North Pacific and North Atlantic-why in som years so much more pronounced than in others?

An important point will be-what conditions appea most favorable for the development of Low areas? In an address before the Royal Soclety of Canada in 1914 the writer said: "We do know, however, some thing of the conditions which are very obviously connected with the development of cyclones, perhaps, indeed we have more certain knowledge regarding this than of any other meteorological activity, e. $g$. , in the colder seasons when cold continental winds in the rear of a shallow trough of low pressure reach the coast line of the Gulf of Mexico or the middle Atlantic, there is almost certain to be a marked storm development with heavy precipitation. Moist warm air of the Gulf Stream on the one side and cold continental ai on the other, lead to a rapid cyclonic development and the greater the contrast in temperature, the more pronounced will be the storm." It is clear that warm moist air is a most important factor, and the warme and moister it is, the better are the conditions for cyclonic development.

The writer believes that the time now is when in creased investigation should be carried on regarding the changes, both in the position and temperatures of the great ocean currents. If It can be shown that the great Japan Current in some years carrles its warm waters further north than in other years, it may no improbably be subsequently shown that in such years cyclonic conditions are more intense near the Alaska coast, and we shall at once have valuable informatio regarding the probable distribution of barometric pres sure in Northwestern $A$ merica, and this appears to be a dominating factor in the character of our winte

In the bulletin of the Seripps Institution for Biological Research, November 8, 1918, Mr. George F. Mc Ewen reviews the various theories of the cause of oceanic circulation from ancient times to the present. oceanic circulation from ancient times to the present. surves of the ocean currents and their variation in position in different years.

While it would appear probable that conditions that would increase the temperature and the flow of ocea currents would act simultaneously in both hemispheres, it does not necessarlly follow that the effect on the northern coast of Europe would occur simultaneously with the effect on the northwest coast of America. One would surmise that as the source of the Gulf One would surmise that as the source of the Gulf
Stream is nearer the Britlsh Isles than is the source of the Japan Current to Alaska, therefore Europe would be affected before America and quite possibly this is the case. The whole question is complex but well worthy of study.

\section{Microstructure of Iron in Electric Welds}

LAST year Mr. S. W. Miller contributed a paper to the American Institute of Mining Engineers on "Structures in Steel Fusion Welds," during the discussion of which various conflicting opinions were expressed as to the nature of the small needle crystals observed in oxy-acetylene and electric welds. The discussion in duced Mr. F. G. Comstock of Niagara Falls, further to examine a weld made on a piece of steel plate, $\%$ in. thick, on which iron had been deposited to a depth of $3 / 16$ in. by arc welding; the weld appeared very good, and did not show any boundary between the plate and the iron. Sections were cut in three planes at right angles to one another through the deposited metal and the steel plate underneath. The polished sections showed round gray oxide spots and after etching with nitric acid also the pale needle crystals of what Miller regarded as cementite, Jeffries as martensite, and Ruder and Boylston as iron nitride. Onder the microscope the boundary between the steel and iron became sharp; the steel immediately underneath the weld appeared coarse-grained, lower down it was flner. Small sections were then cut; the one was annealed at $500^{\circ}$ C. (i. $e$., below the critical temperature of the steel), and the other at $900^{\circ}$ (above that point); the forme was cooled in lime, the latter slowly cooled in the furnace. The fine micrographs of the sections obtained are reproduced in the January, 1919, Bulletin of the Institute. Analyses of flings were also made, and as only 0.04 per cent. of carbon was found, Comstock concludes that the pale crystals cannot be ce mentite or martensite, but are probably iron nitride. This conclusion is supported by etching tests made with sodium picrate and by the detailed study of the micrographs which indicated that the needles when slowly cooled after annealing diffused into the steel but did not merge into the pearlite of the steel. Direct evidence in favor of the nitride formation is however, not given.-Engineering (London).

\section{Ageing of Mercury Vapor Lamps}

W. Coblentz, B. Long, and $\mathbf{H}$. Kahler have determined the decrease through age of the ultra-violet radiation of quartz mercury vapor lamps. The intensities have been measured by means of a bismuth-silver thermo-electric couple and a galvanometer. A water vat, $1 \mathrm{~cm}$. thick, with a quartz window in front of the thermo-electric couple absorbed the infra-red rays of great wave-length $(\lambda>1.4 \mu)$ emitted by the electrodes and the envelope. The complex pencil of rays may be considered as emitted by the mercury vupor; its spectrum consists of intense lines in the ultra-piolet region in the visible part and in the infra-red up to towards $1.4 \mu$. The ageing of the lamps is due to the blackening of the quartz or to a kind of crystallisation, which renders it less transparent to ultra-violet rays.

The simplest method of studying the ageing of the lamp would consist in using a screen transmitting all the $U . V$. rays and absorbing the visible or infra-red rays, or vice versa, but no such ideal screen exists. The authors have, however, used a dark yellow glass (Corning Noviol, shade B) which absorbs all the $0 . V$. rays having a wave-length less than $0.4 \mu$ and whose transmission does not depend upon the power absorbed by the lamp (between 100 and $200 \mathrm{~W}$.). The deviations of the galvanometer caused by the thermo-couple were measured (1) directly after the passage through the water bath, which stops the radiations of great waivelength emitted by the tube walls the yellow glass. The rates of these deviations or transmission coefficient increases as the proportion of U.V. rays decreases, that is, as the tube gets older.
The trials were carried opt with lamps made by the Cooper-Hewitt Co. and the R.D.v. Co. The following results were obtained: (1) the proportion of radiated U.V. rays with a wave-length of $1.4 \mu$ (upper limit) which is 70 per cent. In a new lamp, becoming 50 per cent. after 1,000 to 1,500 hours' working; (2) during the first 500 hours there is no perceptible difference between the percentages of $0 . V$. rays emitted by both types of lamps; (3) the total radiation of the lamps decreases by one-half or one-third of its initial value after 1,000 or 1,200 hours of working.-Reine générale de l'Electrictté. 